as a first-line treatment is one of efficacy. They found $23 \%$ of patients with severe or very severe social phobia treated with moclobemide for eight weeks were rated as much or very much improved $(\nu .0 \%$ in the placebo group), although numbers were too small to reach statistical significance. This finding of greater efficacy in more severe social phobia is also supported by the International Multicenter Clinical Trial Group on Moclobemide in Social Phobia (1997) who found patients with severe social phobia treated with $600 \mathrm{mg}$ moclobemide had a $52 \%$ response rate $(v$. $32 \%$ on placebo).

International Multicenter Clinical Trial Group on Moclobemide in Social Phobla (1997) Moclobemide in social phobia. A double-blind, placebo-controlled Clinical study. European Archives of Psychiotry and Clinicol Neuroscience. 247. 71-80.

Schneier, F. R., Goetz, D., Cumpens, R., et ol (1998) Placebo-controlled trial of moclobemide in social phobia. British journol of Psychiatry. 172, 70-77.

Woiller, E., Bisserbe, J. C., Boyer, P., et ol (1996) Social phobia in general health care. An unrecognised under treated disabling disorder. British journal of Psychiotry. 168, 169-174.

R. Duffett The Royal London Hospital (St Clement's) 2A Bow Road, London E3 4LL

\section{Liaison between adolescent and adult services in early-onset schizophrenia}

Sir: Pelkonen et al's (1998) follow-up study of occupational functioning of adolescent in-patients emphasises the importance of active intervention in early adulthood in those with psychotic disorders. However, they do not highlight the importance of close liaison between adolescent and adult services in order to achieve this. In clinical practice there is lack of clarity about which service should serve those aged 16-18 years. Traditionally, this had depended on the young person's educational status at the time of presentation. However, some 16 to 18-year-olds may have left school as a result of developing psychosis. Their needs in terms of re-integration into educational services and addressing family issues (such as expressed emotion interventions) may be better met by the resources of adolescent services.

Poor psychosocial outcome in adulthood in those with adolescent psychotic disorders is a robust finding (Gillberg et al, 1993). Although early-onset schizophrenia is more likely to be associated with a poor prognosis than adult-onset schizophrenia is (Jacobsen \& Rapoport, 1998) this could be partly ameliorated by commencing treatment early (Turetz et al, 1997) and the potentially greater compliance with atypical antipsychotics. Familiarity with, and experience of, use of atypical antipsychotics by adolescent psychiatrists can be enhanced by liaison with colleagues in adult services.

Close liaison between services at an early stage, therefore, has potential benefits for both services and, particularly, for the young person in terms of addressing all aspects of care and providing continuity of follow-up into early adulthood. The personal and economic implications of years of functional impairment and disability are too great to ignore.

Gillberg. C. Hellgren, L. \& Gillberg, C. (1993) Psychotic disorders diagnosed in adolescence: outcome at age 30 years. Journol of Child Psychology and Psychiatry. 34. $1173-1185$.

Jacobsen, L. K. \& Rapoport, J. L. (1998) Research update. Childhood-onset schizophrenia: implications of clinical and neurobiological research. Journol of Child Psychology and Psychiatry, 39, 101-113.

Pelkonen, M., Marttunen, M., Pulkkinen, E., et of (1998) Disability pensions in severely disturbed inpatient adolescents. Twenty-year prospective study. British journal of Psychiatry, 172, 159-163.

Turetz, M., Mozes, T., Toren, P., et al (1997) An open trial of clozapine in neuroleptic-resistant childhoodonset schizophrenia. British Journal of Psychiatry. 170 $507-510$.

K. Sayal Kings College Hospital, Denmark Hill, London SE5 9RS

\section{Somatoform dissociation is unlikely to be a result of indoctrination by therapists}

Sir: In a previous letter (Nijenhuis et al, 1997) we reported that high scores on instruments measuring dissociation were typical of patients with dissociative disorder and not of those with bipolar disorder. We argued that these data show that dissociative disorders are highly unlikely to be a result of misinterpretation of bipolar disorder. Merskey (1997) commented that our comparison is worthless. Assuming that dissociative disorders results from indoctrination by therapists, he maintained that we have compared un-indoctrinated bipolar patients and indoctrinated 'dissociative' patients.
This assumption is incorrect. For the patients with dissociative disorders we had two groups: one received the Somatoform Dissociation Questionnaire (SDQ-20; Nijenhuis et al, 1996) prior to, and the other after, the administration of the Structured Clinical Interview for Dissociative Disorders (SCID-D) and diagnosis of 'dissociative identity disorder' or 'dissociative disorder not otherwise specified'. The former group cannot possibly have been indoctrinated. Interestingly, patients from the first group who were unaware of their diagnosis tended to obtain higher SDQ-20 scores than those who were aware of their psychiatric status and who were exposed to therapy (further details available from the author upon request).

The a priori assumption that the diagnosis of dissociative disorders must follow from indoctrination seems to be based on prejudice instead of research findings.

Merskey, H. (1997) Tests of 'dissociation' and mood disorder (letter). British journal of Psychiotry, 171, 487.

Nijenhuls, E. R. S., Spinhoven, P., van Dyck, R., et ol (1996) The development and the psychometric characteristics of the Somatoform Dissociation Questionnaire (SDQ-20). Journol of Nervous and Mentol Diseose, 184, 688-689.

_. . . . et ol (1997) Dissociative pathology discriminates between bipolar mood disorder and dissociative disorder. British journol of Psychiatry. 170. 581 .

E. R.S. Nijenhuis, R. van Dyck Department of Psychiatry, Vrije Universiteit at Amsterdam, Valeriusplein 9. 1075 BG Amsterdam. The Netheriands

O. van der Hart Department of Clinical Psychology and Health Psychology, Utrecht University, The Netherlands

P. Spinhoven Department of Psychiatry, Leiden University, The Netherlands

\section{Can transsexualism remit?}

Sir: The subject of the paper by Marks \& Mataix-Cols (1987) is a current patient of ours; Professor Marks was aware of this and discussed this before writing his report, though this is not acknowledged in the paper.

Since the paper contains statements at variance with our understanding of the case, we showed the paper to the patient, who told us of cross-dressing since age 7, self-view as female age 12 , and active search for gender reassignment since age 